REVISTA DE DERECHO UNED, núm. 5, 2009

\title{
LA JUSTICIA COMO AMPLIACIÓN DE LEALTADES EN LA FILOSOFÍA JURÍDICA DE RICHARD RORTY
}

\author{
Rafael Enrique Aguilera Portales*
}

"Los impulsos angélicos y las ansias depredatorias dividen nuestro corazón, exactamente igual que dividen el de otros países».

William James, Pragmatismo

Resumen: La expresión prioridad de la democracia sobre la filosofía expresa de forma clara y contundente su fuerte pragmatismo político antifundacionalista. La defensa de una política sin teoría, verdad o fundamento filosófico responde a una visión contingente de la democracia como sistema político experimental donde no poseemos certezas absolutas ni indubitables. La tarea de inclusión en el nosotros, para Rorty, tiene un fundamento más emocional que racional. Este ejercicio de ampliación de lealtades supone una transformación sentimental basada en emociones que relativizan las diferencias culturales, raciales o de género mediante un trabajo de comprensión del otro, el diferente, el extraño. Rorty desconfía de todo tipo de universalismo político y jurídico. El pragmatismo ironista concibe el universalismo como una plataforma camuflada de esencialismo antropológico. El problema de la fundamentación de los derechos humanos, para Rorty, es una cuestión filosófica trasnochada, pasada de moda, carente de sentido que nos remite inmediatamente a iusnaturalismos trascendentes, teológicos o racionales seculares que debemos superar definitivamente.

* Coordinador y Profesor del Área de Filosofía del Derecho del Centro de Investigaciones Jurídicas y Criminológicas de la Universidad Autónoma de Nuevo León (UANL), Monterrey, Doctor en Filosofía por la Universidad de Málaga, 
Palabras clave: pragmatismo, justicia, derechos humanos, esencialismo, contingencia, universalismo.

Abstract: The phrase «priority of democracy over philosophy» clearly and strongly expresses its own political pragmatism against foundations. The defense of politics without a theory, truth or philosophical base is the result of a view of democracy as an experimental political system where there are no absolute or clear certainties. In Rorty's opinion, the duty of inclusion in the concept of «us» has an emotional foundation -rather than a rational one. This exercise of expanding loyalties is the outcome of a sentimental transformation, based in emotions that make cultural, racial or gender differences, a group of relative situations, via another exercise of comprehension of the other, the different or the strange. Rorty has stopped trusting all types of political or juridical universalism. The ironic pragmatism conceives universalism as a camouflaged platform of anthropological essentialism. The problem with setting a starting point for human rights, in the same author's opinion, is an obsolete philosophical matter that doesn't make sense, which immediately reminds us of transcending, theological or rational natural laws, which we must definitely overcome.

Key words: pragmatism, justice, human rights, essentialism, contingency, universalism.

Sumario: 1. La concepción de justicia en el pensamiento de Rorty.-2. Universalismo político y jurídico de los derechos humanos.-3. Crítica al fundacionalismo de los derechos humanos.-4. Consecuencias políticas y jurídicas del pragmatismo rortyano.-5. Liberalismo ironista, contingencia y comunidad política.

\section{LA CONCEPCIÓN DE JUSTICIA EN EL PENSAMIENTO DE RORTY}

El problema de la justicia constituye un tema fundamental, central y hegemónico de la Teoría Política y Jurídica clásica y contemporánea; sabemos que detrás de todo sistema político y jurídico subyace siempre una teoría de la justicia, es decir, una concepción del mundo, una concepción del hombre, un sistema de valores éticos, políticos y jurídicos que impregnan el modelo de sociedad democrática. Por otro lado, somos conscientes que pocas ideas han despertado tantas discusiones, controversias y debate intelectual como la concepción de justicia. Pero, ¿qué es la justicia? ¿Una idea, un procedi- 
miento equitativo, una virtud moral, una regla social? Sin duda, ninguna idea a lo largo de la historia del pensamiento ha hecho correr tantos ríos de tinta, tantas energías, luchas y pasiones como la concepción de justicia. La justicia se convierte, de este modo, en un valor omnicomprensivo, relevante y esencial para la Filosofía jurídica y política, a la vez que un criterio básico de legitimación, revisión y crítica constante de nuestras instituciones políticas y jurídicas. Para Platón, la justicia constituía la virtud fundamental del hombre y del Estado, de la cual derivan todas las demás virtudes, pues constituye el principio armónico y ordenador de todas (prudencia o sabiduría, fortaleza o valentía, templanza). El Estado justo consistía en el equilibrio y armonía de las distintas clases sociales que componían la sociedad. Aristóteles afirmaba que ni la estrella vespertina ni la matutina son tan maravillosas como la justicia.

El pensamiento político de Rawls ha tenido especial repercusión, bajo el título de Teoría de la Justicia, ha construido en realidad, más que una teoría de la justicia, una teoría de la democracia liberal, que se ha identificado nada menos que con la justicia. Partiendo de lo que él denomina los dos principios de justicia, que en realidad no son sino la condensación de las premisas ideológicas que están en el origen de la democracia liberal. Aunque, debemos precisar que el desorden socio-político tiene multitud de niveles, factores y causas y resulta absurdo pretender que una simple teoría normativa pueda solventar dicho desorden tan complejo como el entramado jurídicosocial.

En este sentido, John Rawls afirma que «la justicia es la primera virtud de las instituciones sociales». La justicia está relacionada, por tanto, con la idea de asignación de derechos y obligaciones, o beneficios y cargas de los distintos individuos de un determinado grupo social. Por eso, el objeto primario de la justicia es la estructura básica de la sociedad, es decir, como las instituciones sociales más importantes que regulan la distribución de los derechos y deberes fundamentales y las ventajas derivadas de la cooperación social. En este sentido, los dos principios de la justicia serían el principio igualdad al más amplio sistema de libertades básicas (libertad de pensamiento, conciencia...) y el principio de diferencia que estructure las desigualdades económicas y sociales hacia un mayor beneficio de los más desfavorecidos (justa igualdad de oportunidades). Igualmente, para John Rawls, una sociedad bien ordenada lo es no sólo cuando está diseñada para promover el bien de sus miembros, sino cuando está regulada efectivamente por una concepción de justicia como equidad. Rawls señala que nuestras sociedades no están bien ordenadas y 
que, por tanto, es necesario proceder a una reconstrucción del entramado normativo que pueda reorganizarlas.

Rorty admira a Rawls porque permanece en la superficie filosóficamente hablando y no busca fundamentos filosóficos que justifiquen el modelo democrático. Para Rorty «una teoría de la Justicia» no tiene que ofrecer una interpretación del ser humano, sino una descripción histórico-sociológica de la forma política en que vivimos. En este sentido, la gran obra Teoría de la justicia de Rawls es asumida desde una perspectiva más política que metafísica ${ }^{1}$.

La Filosofía política y jurídica rortyana prescinde de todo intento fundacionalista porque considera absurdo buscar premisas teóricas que justifiquen la democracia liberal. Por tanto, no necesitamos argumentos, interpretaciones e ideas para fundamentar la democracia, sino estrategias de poder encaminadas hacia su ampliación y consolidación institucional. La expresión prioridad de la democracia sobre la filosofía expresa de forma clara y contundente su fuerte pragmatismo político antifundacionalista. La defensa de una política sin teoría, verdad o fundamento filosófico responde a una visión contingente de la democracia como sistema político experimental donde no poseemos certezas absolutas ni indubitables. En este sentido, somos un experimento individual y colectivo permanente, donde no hay nada definitivo y todo está por hacer. El pragmatismo liberal ironista insiste en la ausencia de cualquier premisa o presupuesto metafísico, religioso o filosófico como aspecto central de su teoría política. En esta línea, Rorty critica la pretensión de Habermas de encontrar un punto de vista por encima de la política para garantizar y fundamentar la superioridad de la democracia ${ }^{2}$ como sistema político superior por excelencia. Habermas piensa que sigue existiendo una fuerte conexión entre democracia, universalismo y racionalismo, mientras Rorty disiente profundamente de esta concepción de cone-

1 RAWLS, J., A Theory of Justice, Oxford, 1972 (ed. Cast. Teoría de la Justicia, trad. De M.d. González, México, FCE, 1993); Rawls evoluciona desde sus primeros escritos hacia una teoría de la justicia que tome en cuenta el «pluralismo social razonable» de la sociedad contemporánea hacia su segunda gran obra RAWLS, J., El liberalismo político, Barcelona, Crítica, 1996. En este sentido, se ha hablado de giro político de su pensamiento hacia un segundo Rawls, en dichas sociedades plurales es preciso y necesario una concepción política de justicia que sustente el Estado constitucional.

2 Habermas desarrolla una teoría pragmática-universal donde se proporciona especificación sobre las pretensiones de validez inmersas en un sistema de comunicación y una diferenciación de los usos del lenguaje y de los distintos géneros de discurso especializados. Desde esta perspectiva, critica todos los planteamientos deconsruccionistas de Derrida, Rorty y Paul de Man. Véase HABERMAS, J., El discurso de la modernidad (trad. de M. Jiménez Redondo), Taurus, Madrid, 1987. 
xión. En este sentido, cree que no es posible derivar una política democrática de una filosofía política o una filosofía del lenguaje. No existe nada en la naturaleza del lenguaje o de la política que pueda justificar la superioridad de la democracia liberal. Sin duda, su desacuerdo es más teórico (búsqueda de fundamentos), que político; pues ambos pensadores comparten el proyecto político de la Ilustración a través del ideario democrático y la conquista de los derechos humanos; aunque disienten en la visión, justificación, desarrollo y alcance del mismo. Por esta razón Richard Bernstein afirma: «La etiqueta que yo usaría para darle nombre al proyecto común de Rorty, Habermas y Gadamer es la de "humanismo pragmático no fundacional" ${ }^{3}$.

Rawls no desea una visión deontológica completa, que explicase por qué debemos dar a la justicia la prioridad sobre nuestra concepción del bien. Rawls no se interesa por las condiciones de la identidad del yo o localizar una determinada concepción antropológica, sino solamente por las condiciones de la ciudadanía en una sociedad liberal. Rawls no trata de proporcionar un fundamento filosófico a las instituciones democráticas ${ }^{4}$, sino que simplemente intenta sistematizar los principios, valores e intuiciones característicos del liberalismo político norteamericano.

En esta línea, Rorty señala basándose en Jefferson que al igual que este pensador se negó a que las escrituras cristianas fuesen la base de las instituciones políticas liberales, nosotros debemos sustituir la pregunta: ¿qué tipo de ser humano deseáis crear?, por otra cuestión: ¿es primaria la justicia? o ¿qué fundamento podemos encontrar a nuestras instituciones políticas y jurídicas?

El pragmatismo rortyano nos plantea dilemas morales como conflictos entre lealtad y justicia, donde tenemos que decidir entre la le-

${ }^{3} C f r$. BERNSTEIN, Richard, «¿Cuál es la diferencia que marca una diferencia? Gadamer, Habermas y Rorty» en Perfiles filosóficos, México, Siglo XXI, 1991, p. 104; Véase también MARRONE, Pierpaolo, «Los intentos de una nueva fundación: neoliberalismo, neocontractualismo, comunitarismo» en DUSO, Giuseppe (cood.), Para una historia de la filosofía política, México, Ed. Siglo XXI, pp. 367-390.

${ }^{4}$ Rawls propugna un consenso entrecruzado (overlapping consensus) entre los distintos actores, ciudadanos y grupos políticos: «la profundidad de un consenso entrecruzado requiere que sus principios e ideales políticos se funden en una concepción política de justicia que haga uso de ideas fundamentales de la sociedad y de la persona como las que ejemplifica la justicia como equidad». Cfr. RAWLS, J., El liberalismo político, (trad. cast. A. Doménech), Barcelona, Crítica, 1996, p.196. Cuanto más restringido sea el espectro de grupos políticos, más específico será el consenso, pues van a existir concepciones políticas rivales de justicia constitucional. 
altad expresada como sentimiento a un grupo pequeño y la justicia expresada como el ideal de lo que sería mejor, hacia una grupo ampliado proveniente del uso de la razón. Conflictos entre grupos más pequeños o más amplios.

Los pensadores neokantianos como Habermas insisten en que la justicia surge de la razón ${ }^{5}$ y no de la lealtad o el sentimiento. La razón impone obligaciones morales incondicionales y universales, como por ejemplo ser justos, equitativos e imparciales. Habermas trata de no oscurecer la demarcación entre razón y sentimiento, racionalidad y voluntad, validez universal y consenso histórico. Otros filósofos políticos y jurídicos contemporáneos se alejan de esta concepción de justicia propuesta por Kant, bien en la dirección de Hume (Annette Baier), bien en la posición de Hegel (Charles Taylor) ${ }^{6}$, bien en la postura de Aristóteles (Alasdair MacIntyre) ${ }^{7}$.

La tarea de inclusión en el «nosotros», para Rorty, tiene un fundamento más emocional que racional. Este ejercicio de ampliación de lealtades supone una transformación sentimental basada en emociones que relativizan las diferencias culturales, raciales o de género mediante un trabajo de comprensión del otro, el diferente, el extraño. La solidaridad humana no consiste en el reconocimiento de un yo nuclear -la esencia humana - en todos los seres humanos. Se la concibe como la capacidad de percibir cada vez con mayor claridad que las diferencias tradicionales (de tribu, de raza, de costumbres) carecen de importancia cuando se las compara con las similitudes referentes al dolor y la humillación. Y aquí el intelectual moderno puede realizar una contribución al progreso moral a través de descripciones detalladas de variedades particulares de dolor y humillación (contenidos en novelas e informes etnográficos) más que tratados filosóficos y teológicos.

5 HABERMAS, J., Facticidad y validez, Madrid, Trotta, 1998.

6 TAYLOR, Charles, Ética de la autenticidad. Paidós, Barcelona, 1998, p.213. TAYLOR, Charles: Multiculturalism and «the politics of recognition», A. Gutman ed. Princeton, Princeton University Press, 1992.

7 MACINTRYE, Alasdair, Tras la virtud, Barcelona, Crítica, 1987. El retorno a la racionalidad de lo moral, según MACINTYRE, pasa por el retorno a la premodernidad, porque el proyecto moderno - a su juicio- conduce necesariamente a Nietzsche, es decir al emotivismo, nihilismo y subjetivismo solipsista. Por tanto, es preciso y urgente una regeneración del neoaristotelismo, porque Hume, Kant, Mill no proporcionan una vía alternativa posible en nuestras sociedades contemporáneas. En mi opinión, MacIntyre se equivoca de terapia aunque no de diagnostico socio-político. Tal vez el emotivismo moral no sea el resultado necesario del proyecto moral ilustrado, sino justamente una desviación o tergiversación incorrecta de éste. 
El pragmatismo liberal rortyano no niega que exista un progreso moral y que ese progreso se oriente en realidad hacia la dirección de una mayor solidaridad humana. Rorty piensa que para alcanzar este progreso moral e intelectual resulta más útil y preferible pensar desde una moral etnocéntrica pragmática y sentimental ${ }^{8}$, que desde una moral universalista y racionalista como la moral kantiana. Sin duda, los términos abstractos e ideales como "hijo de Dios» o "humanidad», o «ser racional» han realizado mucho bien históricamente en la mejora de la sociedad y, por tanto, han propiciado el camino para el cambio político, moral y cultural de nuestras sociedades democráticas occidentales. Pero, hoy en día, estas nociones, en primer lugar, pertenecen a vocabularios antiguos de otra época, en segundo lugar, adolecen de una excesiva dosis filosófica abstracta y artificialidad $\mathrm{y}$, por otro lado, invitan a cuestionar y dudar acerca de la noción de solidaridad humana, como así lo hizo Nietzsche con su escepticismo moral $^{9}$.

Si continuamos ampliando nuestro sentimiento de «nosotros» tanto como podamos al resto de los seres humanos, entonces la pregunta inútilmente escéptica "¿es real la solidaridad?» deja de tener sentido. De esta forma Rorty está planteando una nueva concepción de solidaridad como el intento de ampliar el ámbito del nosotros tanto como podamos viendo similitudes entre el «ellos» y el «nosotros». En consecuencia, no podemos partir del lugar en el que no estamos, como hacen las éticas universalistas, cuando hablan de entidades abstractas como «la humanidad», "todos los seres racionales», porque nadie puede llegar a una identificación con estas abstracciones. «[...] la identificación me parece imposible: una invención

${ }^{8}$ La moral etnocéntrica sentimental o pragmática es una moral anti-universalista, anti-racionalista y anti-esencialista, una moral que presupone que existe un progreso moral encauzado a lograr una mayor solidaridad, no de tipo esencialista (razón universal) sino de empatía emocional y sentimental, del reconocimiento del sufrimiento y el dolor del otro.

9 El escepticismo moral nietzscheano consiste en una postura escéptica hacia la moral de la cultura europea, los valores cristianos, el socialismo y el igualitarismo democrático, en la cual Nietzsche sustenta que estos ideales son sólo una forma de moral que debe de ser superada mediante una visión situada más allá del bien y del mal. Este escepticismo sospecha de la moral que Nietzsche califica de vitalidad descendente, oponiéndole a ésta la voluntad de vivir y consecuentemente la voluntad de poder. En esta actitud, la vida se opone a los demás valores como valor supremo, puesto que la voluntad de vivir es la mayor oposición posible a la objetividad, igualitarismo, conmiseración y a la piedad de tipo cristiano. Vid., AGUILERA PORTALES, Rafael Enrique, «El horizonte político en el pensamiento de Nietzsche» en CASTILLA, Antonio (coord.), Nietzsche y el espiritu de ligereza, México, Ed. Plaza y Valdés, 2007. 
de filósofos, un torpe intento de secularizar la idea de llegar a ser uno con Dios» ${ }^{10}$.

En este sentido un planteamiento crítico al ideal de autonomía kantiano lo podemos encontrar en el pensamiento moral de Annette Baier, filósofa norteamericana contemporánea ${ }^{11}$, intelectual feminista de Estados Unidos, que sigue la tradición emotivista y utilitarista de David Hume. Esta pensadora considera los sentimientos y la sentimentalidad como centrales de la conciencia moral. Baier propone que sustituyamos como concepto moral fundamental la noción de «obligación» por la de «confianza apropiada». De este modo nos dice: "para la filosofía moral el villano es el racionalista, la tradición de la ley fija, que opina que detrás de toda intuición moral yace una regla universal» ${ }^{12}$.

Para la filósofa Annette Baier la moralidad comienza, no como obligación, sino como una relación de confianza entre los miembros de un grupo estrechamente vinculado, como un grupo social, una familia o un clan. Así las familias se confederan en tribus, y las tribus en ciudadades y las ciudades en naciones. De esta forma lo que Kant describiría como un conflicto entre obligación moral y sentimiento, según una visión no kantiana, sería un conflicto entre un conjunto de lealtades y un conjunto de simpatías.

«La idea de obligación moral universal de respeto a la dignidad humana es reemplazada por la idea de lealtad a un grupo muy amplio: la especie humana» ${ }^{13}$.

En consecuencia, los iusfilósofos kantianos se equivocan al creer que la prudencia (phrónesis) consiste en el resultado de hacer más densos los principios morales abstractos. En este aspecto, Michael

10 RORTY, R.: Contingencia, ironía y solidaridad, Barcelona, Paidós, 1991, p. 216.

11 Su filosofía moral está articulada y vertebrada por el pensamiento de Hume, acentuando la importancia del lugar que tiene la confianza en la moral. En esta línea Baier ha expuesto los inconvenientes del ateísmo en la ética y la epistemología argumentando que lo que necesitamos es fe (confianza) en la comunidad humana y en su propio desarrollo. Annette Baier sostiene que tiene que existir una coherencia entre las conductas propias y las observaciones y reclamos que otros realizan sobre nosotros, un problema que remite a temas que nuestra pensadora piensa indispensables, como la honestidad, la complejidad de las emociones y el problema de la confianza entre mujeres. Vid., DE LORA DEL TORO, Pablo, «Annette Baier y Michael Walzer: acerca de la ética normativa y la filosofía moral» en DOXA, Revista de Filosofía del Derecho, Universidad de Alicante, n. ${ }^{\circ}$ 15-16, 1994, pp. 599-634.

12 BAIER, Annette: Postures of the Mind, Minneapolis: University of Minnesota Press, 1985, p. 232.

${ }^{13}$ RORTY, R.: Pragmatismo y política (trad. Rafael del Aguila) Barcelona, Paidós, 1998, p. 102. 
Walzer distingue la moralidad densa de la moralidad tenue ${ }^{14}$, o sea un contraste entre historias concretas y detalladas que pueden estar cerca de nosotros, y una historia esquemática y abstracta que puedes contar como ciudadano del mundo.

Para Rorty y los pensadores comunitaristas el concepto de justicia desde su contextualismo extremo está íntimamente ligado a la noción de bien y no cabe separación posible. Sin embargo, Rorty junto a Michael Walzer, están proponiendo una concepción pluralista de justicia, y critican el ideal de «igualdad simple» porque necesitaría la intervención del Estado. Sin embargo, esta concepción de igualdad es muy "simplista» y no resuelve las demandas de los nuevos movimientos sociales y las enormes desigualdades provocadas por el mercado capitalista liberal.

Por esta razón Michael Walzer postula una «igualdad compleja», que nos conduce a una «justicia compleja». Pero ello puede conducir, no ya al pluralismo social, sino al relativismo generalizado, si no se adoptan cautelas para que se mantenga, al menos, una justicia mínima, generalmente compartida. La "justicia en las esferas» no se opone sino que más bien supone, una teoría de la justicia básica. Mientras los liberales inciden, de forma especial, en los procedimientos, los comunitaristas inciden en los bienes compartidos que alimentan la justicia.

Los comunitaristas argumentan que la teoría liberal desfigura la vida real. No podemos entender un mundo donde hombres y mujeres estén desligados de todo tipo de relaciones sociales, literalmente sin compromisos $^{15}$. Michael Walzer enfatiza el carácter pasajero, efímero y contingente de las sociedades capitalistas occidentales. Los individuos de estas sociedades están continuamente en un proceso de movilidad. La movilidad geográfica impide la formación de comunidades, puesto que el desarraigo es mayor. La movilidad social ${ }^{16}$, las sociedades actuales postmodernas han cambiado de normas, costumbres, usos sociales ocasionando un choque generacional mayor.

14 WALZER, M. Esferas de la justicia, México, F.C.E., 1993; WALZER, Michael, Interpretation and Social Criticism, Cambridge (Massachusets), Harvard University Press.

15 Vid., AGUILERA PORTALES, Rafael, «El debate iusfilosófico contemporáneo en torno a la ciudadanía entre liberales, republicanos y comunitaristas y republicanos» en Anuario de Derecho Universidad de Alcalá de Henares, Universidad Alcalá de Henares, Madrid, 2006, pp. 6-44.

16 Vid., BELL, D.: Las contradicciones culturales del capitalismo. Alianza, Madrid, 1977. Véase también su estudio más reciente BELL, Daniel: El advenimiento de la sociedad postindustrial, Alianza, Madrid, 1986. 
La movilidad matrimonial ha incrementado el número de separaciones, divorcios que merman la comunidad familiar, primera instancia educativa y socializadora del niño. Y la movilidad política con el cambio de ideologías, partidos, líderes, instituciones que afectan también al ámbito económico.

Rawls igualmente diferencia las concepciones de justicia ${ }^{17}$ densas y las concepciones de justicia significativas cuando establece distinciones entre gente que importa más y gente que importa menos, estas divisiones son prioritarias en el funcionamiento de nuestros juicios morales, políticos y jurídicos. Rorty destaca que a Rawls le gustaría reivindicar la universalidad, pero que no se puede desprender en su trabajo de un cierto historicismo. La propuesta constructivista surge cuando esa ley es aplicable sólo a pueblos razonables. Rawls no puede rechazar el historicismo y al mismo tiempo invocar esta noción de razonabilidad.

Rorty está de acuerdo con Habermas cuando afirma que lo que Rawls de hecho prejuzga en el concepto de "consenso superpuesto» 18 es la distinción entre formas de conciencia modernas y premodernas, entre concepciones del mundo «razonables» y «dogmáticas». Esta idea constructivista social de Rawls podría funcionar si adoptara un contextualismo fuerte.

Esta concepción de racionalidad occidental fuerte es negada por Walzer, porque no existe un tribunal transcultural de la razón ante el cual pueda disolverse esta cuestión. Michael Walzer da por sentado que no existe la superioridad epistémica de la idea occidental de razonabilidad. Y presupone un contextualismo fuerte en el que no hay una única «racionalidad».

En este sentido Rawls y Habermas invocan la noción de «razón» mientras que Walzer casi nunca lo hace. En Habermas esa noción siempre está ligada a validez independiente del contexto. Rawls distingue entre lo razonable y lo racional. Pero ambos planteamientos

17 En su obra posterior El liberalismo político, Rawls presentaba un modelo de relación entre las nociones de bien y la idea de justicia, que en términos liberales, podemos entender como el contraste entre lo privado y lo público, lo ético y lo político. Vid., RALWS, J., El liberalismo político, Barcelona, Crítica, 1996.

${ }_{18}$ Es importante para Rawls la creación de una unidad social. Una unidad social que no se puede alcanzar sobre el valor de los fines de la vida, pero sí sobre un consenso superpuesto de una concepción razonable de justicia. Y en este sentido, la tarea de la filosofía es proporcionar elementos de aglutinación social que permitan un consenso acerca de los valores mínimos que debemos utilizar en un Estado democrático de derecho. Vid., RAWLS, John, "The Law of People», en S. SHUTE y S. HURLEY (comps.) On Human Rights, 1993, Nueva York, Basic Books, p. 71. 
descansan en la concepción kantiana de la razón práctica. Para ambos existe una facultad humana universalmente repartida llamada razón práctica, que existe antes y trabaja independientemente de la reciente historia de Occidente. Esta razón haría el trabajo de detectar la validez moral transcultural.

Habermas sustituye la razón centrada en el sujeto, por la razón comunicativa $^{19}$; es una forma de sustituir el qué por el cómo. Y se centra en la diferencia entre fuerza y persuasión, en lugar de hacerlo como Platón o Kant, en la diferencia entre dos partes del ser humano: la parte buena racional y la parte dudosa, pasional o sensual.

Cuando llamamos a alguien irracional no afirmamos que esa persona no está haciendo un uso apropiado de las facultades que Dios le otorgó, sino que esa persona no comparte suficientes creencias y deseos relevantes para nosotros en una conversación provechosa. En este aspecto Rorty desecha y descarta la noción kantiana de racionalidad universal fuerte ${ }^{20}$. La admitiría si esta racionalidad fuera invocada para defender que ser racional garantiza una resolución pacífica de los conflictos. Lo que Habermas llama la fuerza del mejor argumento.

«Si dejamos de pensar en la razón como una fuente de autoridad, y pensamos en la simplemente como un proceso de consecución de acuerdos mediante la persuasión, entonces la dicotomía platónica y kantiana entre razón y sentimientos comienza a desvanecerse ${ }^{21}$.

Rorty está de acuerdo en el concepto de lo razonable que plantea Rawls y en su idea del tipo de sociedades que nosotros los occidentales deberíamos aceptar como miembros de una comunidad moral global.

${ }^{19}$ Habermas entiende que la acción comunicativa se desarrolla en el mundo de vida que comprende la tradición cultural compartida intersubjetivamente por una comunidad y constituye el trasfondo de dicha acción comunicativa. Todo proceso de entendimiento tiene lugar sobre el trasfondo de una precomprensión imbuida culturalmente. Vid. HABERMAS (1981) Theorie des Kommunikativen Handelns, 2 vols., Frankfurt, Suhrkamp, trad. castellano Teoría de la acción comunicativa, tomo I, (Racionalidad de la acción y racionalización social), Taurus, Madrid, 1989; véase también el trabajo de SAHUÍ, Alejandro, Razón y espacio público: Arendt, Habermas y Rawls, Ediciones Coyoacán, México, 2002; MUGUERZA, Javier «Ética y comunicación» en Revista Estudios políticos n. ${ }^{\circ} 20$, p. 21.

${ }^{20}$ Rorty como pensador posmoderno se inscribe en la tradición que cuestiona el modelo de racionalidad occidental que arranca de Platón y continua la modernidad con el paradigma de la conciencia cartesiana, en definitiva, su pragmatismo desconfía de las concepciones fuertes de racionalidad.

21 RORTY, R., Pragmatismo y Política, op. cit..., p. 121. 
«Pero creo que la retórica que los occidentales usamos para tratar de hacer a todo el mundo más similar a nosotros mejoraría si fuéramos mas francamente etnocéntricos y menos pretendidamente universalistas. Sería mejor decir: así es como somos en Occidente como resultado de dejar de tener esclavos, de la educación de la mujeres, de separar Iglesia y Estado [...] Decir este tipo de cosas parece preferible a decir: mirad cuán mejores somos nosotros, cuánto más racionales, al saber qué diferencias entre las personas son arbitrarias y cuáles no» ${ }^{22}$.

Los occidentales, según Rorty, deberíamos desechar la noción de obligación moral universal y sustituirla por la idea de construir una comunidad de confianza ${ }^{23}$ entre nosotros y ellos. En este caso, estaríamos en una mejor posición de persuadir a los no occidentales de las ventajas de unirse a nuestra comunidad, por esta razón deberíamos descartar o desprendernos del racionalismo ilustrado residual (herencia de la Ilustración). Esto nos permitiría como ciudadanos occidentales acercarnos mejor a individuos y culturas no occidentales diferentes a la nuestra.

Kant describiría este conflicto como resultado entre la obligación moral y sentimental, entre razón y sentimiento ${ }^{24}$; pero en realidad se trata de un conflicto entre un conjunto de lealtades y otras. De esta forma: "la idea de obligación moral y universal de respeto a la dignidad humana es remplazada por la idea de lealtad a un grupo más amplio: la especie humana. La idea de que la obligación moral, se extiende más allá de la especie, hacia un grupo aún más amplio, se convierte en la idea de lealtad, hacia todos aquéllos que, como uno mismo, pueden experimentar dolor [...]» ${ }^{25}$. En este sentido, los dilemas morales no son el resultado de un conflicto entre la razón y

22 Ibid., p. 123.

${ }_{23}$ El problema de la consolidación democrática tiene que ver con el déficit de legitimación y apoyo social de la ciudadanía hacia las instituciones políticas. Según el politólogo Robert D. Putnam por capital social podemos entender el grado de confianza hacia los otros, así como la capacidad de cooperación entre los individuos, trabajo en equipo, colaboración, delegación de responsabilidades, coordinación grupal. Vid., PUTNAM, R. D., Making Democracy Work. Civic Tradiction in Modern Italy, Princenton, Princenton University Press, 1993; Gesellschaft und Gemeinsinn. Sozialkapital im internactionalien Vergleich, (Sociedad y espíritu cívico. Capital social en comparación internacional), Gûtersloh, Bertelmann, 2001.

${ }^{24}$ KANT, I., Die Metaphysik der Sitten, (trad. Cast.) Kant, I., Metafísica de las costumbres, trad. Cast. A. Cortina y J. Conill, Tecnos, 1994, (2. ${ }^{\text {a }}$ ed.), p.230; Véase también BRANDT, R., "Observaciones critico-históricas al escrito de Kant sobre la paz», en R. R. Aramayo, J. Muguerza y C. Roldán (ed.), La paz y en el ideal cosmopolita de la ilustración, A propósito del bicentenario de Hacia la paz perpetua de Kant, Tecnos, Madrid, 1996, pp. 31-63.

25 RORTY, R., Pragmatismo y Política, op. cit..., p. 109. 
sentimiento sino entre identidades alternativas (selfs), como formas diferentes de dar sentido a la propia vida.

\section{UNIVERSALISMO POLÍTICO Y JURÍDICO DE LOS DERECHOS HUMANOS}

Rorty desconfía de cualquier tipo de universalismo político y jurídico. En contraposición a Habermas que insiste en la necesidad de pensar en términos universalistas, se pregunta: ¿cómo es posible hablar de derechos humanos y no pensar en términos universalistas? El pragmatismo ironista concibe el universalismo como una plataforma camuflada de esencialismo antropológico. «El pragmatismo deja a un lado esa suposición e insta a considerar que la noción de humanidad carece de límites fijos, que la palabra humano nombra un proyecto impreciso pero prometedor, no una esencia $»^{26}$.

No obstante, la universalidad pese a la opinión de Rorty constituye una característica básica y esencial de la formación histórica del concepto y desarrollo histórico de los derechos humanos. El universalismo político y jurídico constituye un componente fundamental de nuestra tradición cultural occidental. Occidente desde sus inicios ha poseído una fuerte vocación universalista tanto por sus intentos de expansión y colonización como por sus intentos de comunicación intercultural y mestizaje en el Mediterráneo. Como afirma el profesor Antonio Enrique Pérez Luño: «El gran invento jurídico-político de la modernidad reside, precisamente, en haber ampliado la titularidad de las posiciones jurídicas activas, o sea, de los derechos a todos los hombres, y, en consecuencia, de haber formulado el concepto de los derechos humanos» ${ }^{27}$.

Los derechos humanos, desde el inicio de la modernidad ${ }^{28}$, han significado un conjunto de facultades jurídicas básicas comunes ${ }^{29}$ a

${ }^{26}$ Cfr. RORTY, R., ¿Esperanza o conocimiento? Una introducción al pragmatismo, Buenos Aires, F.C.E., 1997, p. 50.

27 Cfr. PEREZ LUÑO, Antonio Enrique, Trayectorias contemporáneas de la Filo-

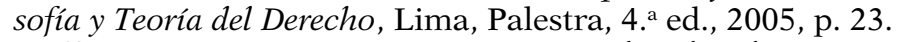

28 TRUYOL Y SERRA, Antonio, Los derechos humanos, Madrid, Tecnos, 1984. Rorty critica el enorme grado de abstracción del cristianismo trasladado al universalismo ético secular. Para Kant, no debemos sentirnos obligados hacia alguien porque es milanés o norteamericano, sino porque es un ser racional. Rorty critica esta actitud universalista tanto en su versión secular como en su versión religiosa. Para Rorty existe un progreso moral, y ese progreso se orienta en realidad en dirección de una mayor solidaridad humana. 
todos los hombres. En consecuencia, un rasgo fundamental que marca el origen de los derechos humanos ${ }^{30}$ es su fuerte carácter y vocación universal.

La tradición empirista-emotivista moral arranca de Hume y se extiende hasta nuestros días. David Hume en su Investigación sobre los principios de la moral nos habla de los «sentimientos de humani$d a d{ }^{31}$, barajando una idea o concepto de dignidad humana presente en todo hombre cuando se produce un atropello o conculcación de los derechos humanos. Estos sentimientos de humanidad compartida y universal nos permiten levantar un muro frente a la brutalidad, la injusticia y el sufrimiento. Estos sentimientos comunes nos permiten un grado de empatía, comprensión y solidaridad ante el sufrimiento ajeno. Y la razón, algo que olvida frecuentemente Rorty, trabaja para el sentimiento, a fin de no caer en un sentimentalismo banal, una manipulación emocional, engaño, ilusión o fantasía. La razón, por tanto, juega un papel importante en la elaboración de un juicio moral. Sin duda, Hume era consciente de que teníamos que dilucidar y reflexionar en torno a las circunstancias que rodean un determinado hecho o una experiencia.

Peter Häberle ha fundamentado el Estado Constitucional a partir de la premisa antropológica-cultural ${ }^{32}$ de la dignidad humana. La dignidad humana es el fin último y objetivo de la organización de todo Estado que se precie de ser constitucional, es decir, que respete los derechos fundamentales y las libertades públicas. El Estado constitucional, de este modo, gira ineludiblemente en torno a esta con-

29 Vid., PÉREZ LUÑO, E., Derechos humanos. Estado de derecho. Constitución, Tecnos, Madrid 1999, (6. ${ }^{\mathrm{a}}$ ed.).

30 ETXEBARRIA, Xavier, "Universalismo ético y derechos humanos» en RUBIO CARRACEDO, J. L. Retos pendientes en Ética y política Revista Malacitana, n. ${ }^{\circ}$. Igualmente consúltese el trabajo donde desarrollo de forma más amplia esta problemática de universalidad de los derechos humanos; AGUILERA PORTALES, Rafael, "Multiculturalismo, derechos humanos y ciudadanía cosmopolita» en Revista LETRAS JURÍDICAS, Universidad de Guadalajara, México, n. ${ }^{\circ}$ 3, Otoño, 2006, pp. 1-29.

${ }^{31}$ David Hume (1711-1776) defiende un escepticismo moderado y racional, no caprichoso y arbitrario, un escepticismo consecuente, fruto de un análisis serio sobre nuestras facultades intelectuales y los límites de nuestro conocimiento. Con todo esto, Hume nos quiere hacer ver que no es la razón quien guía nuestra vida, sino que es la creencia o el hábito; pero esto no quiere decir que Hume niegue la importancia de la razón, aunque es cierto que la relativiza notablemente. Vid., HUME, David, Tratado de la naturaleza humana, Aguilar, Buenos Aires, 1973.

32 Véase especialmente HÄBERLE, Peter, El Estado constitucional, (trad. Héctor Fix-Fierro) Universidad Nacional Autónoma de México, México, 2001. pp. 160-180.

${ }^{33}$ Cfr. ETXEBARRIA, Xavier, "Universalismo ético y derechos humanos», op. cit., p. 127. 
cepción básica y fundamental que posibilita la realización de la persona humana. El conjunto de derechos y deberes al que aspira todo Estado constitucional conforma la cultura jurídico-política esencial de todo ciudadano.

El universalismo político y jurídico de los derechos humanos se puede fundamentar en la experiencia común universal de todos los seres humanos ante la experiencia de injusticia. A lo largo de nuestra vida, todos hemos experimentado o sentido algún tipo de agravio, discriminación o trato desigual hacia nuestra persona o hacia terceras personas. Este sentimiento de indignación o repulsa ética constituye un pilar fundamental desde el cual se construye la verdad trashistórica o trascultural ${ }^{33}$ de la dignidad humana. Esta categoría histórica de la dignidad humana nos muestra la convicción de cómo el ser humano no puede ser usado como medio o instrumento. En cierto sentido, podemos reconocer la contingencia histórica de cómo en otras épocas la esclavitud fue una práctica generalizada y normal, así como la subordinación de la mujer, sin embargo, en la actualidad nadie cuestiona la igualdad común de todo ser humano. La exigencia de universalidad sigue siendo una condición imprescindible y necesaria para el reconocimiento internacional de los derechos inherentes a todos los seres humanos excluyendo cualquier tipo de discriminación o marginación.

\section{CRÍTICA AL FUNDACIONALISMO DE LOS DERECHOS HUMANOS}

El problema de la fundamentación de los derechos humanos, para Rorty, es una cuestión filosófica trasnochada, pasada de moda, carente de sentido que nos remite inmediatamente a iusnaturalismos trascendentes ${ }^{34}$, teológicos o racionales seculares que debemos

${ }^{34}$ El profesor Antonio Enrique Pérez Luño elabora una clasificación muy pertinente a nuestro contexto histórico-intelectual. En primer lugar, tendríamos un iusnaturalismo ontológico, dogmático o radical, que postula un orden de valores producto de un objetivismo metafísico transcendente. El iusnaturalismo ontológico parte de un realismo metafísico ingenuo, esencialista y trascendente que presupone la existencia de un mundo prefabricado (ready-made-World) y presupone la existencia del punto de vista de Dios. La verdad para el realista metafísico es una propiedad no-epistémica, es decir, independiente a las cualidades epistémicas de las teorías. En segundo lugar, el iusnaturalismo deontológico, crítico o moderado que no niega la juricidad del derecho positivo injusto, pero establece los criterios para comprobar su disvalor y, por tanto, para fundamentar su crítica y su sustitución por un orden jurídico justo. Vid., PEREZ LUÑO, Antonio Enrique, Trayectorias contemporáneas de la Filosofía y la Teoría del Derecho, Lima, Palestra, $4 .^{\text {a }}$ ed., 2005, p. 41. 
superar definitivamente. En consecuencia, nos encontramos ante un problema filosófico y antropológico que guarda un cierto sabor a metafísica rancia, caduca y dogmática. En su línea pragmatista, sólo debemos atender a la búsqueda de una utilidad social y política, nunca a intentos de fundamentación teórica.

Pero, desde su pragmatismo ${ }^{35}$ basado en la difusión y propagación de los derechos humanos nos asaltan las siguientes preguntas: ¿Cómo difundir los derechos humanos si no cabe argumentación racional en su defensa?, ¿cómo podemos propagar los derechos humanos de forma eficaz si no podemos ejercer la crítica racional contra la vulneración y conculcación de los mismos?, ¿cómo proteger eficientemente los derechos humanos sin un apoyo sólido y firme que posibilite y explique su elección preferencial?, ¿cómo articular una mayor protección jurídica de los derechos humanos si no podemos articular estrategias fundacionales que ayuden a comprender su enorme valor axiológico-deontológico (ético), político-legitimador (sociológico) y valorativo-interpretativo (iusfilosófico)?

En este sentido, Rorty huye de toda teoría política y jurídica que pretenda argumentar y justificar una cultura sólida y profunda de los derechos humanos. Su miedo antiesencialista le impide ver que precisamos de nociones o léxicos como «humano» $e$ «inhumano», "dignidad», «persona» que nos permitan distinguir un mayor o menor nivel de reconocimiento, respeto y protección de los derechos humanos. Estas nociones nos sirven para profundizar, argumentar y difundir la cultura de los derechos humanos y valorar los diferentes grados de vulneración de los mismos. Toda instancia teórica y conceptual de los derechos humanos permite en la práctica judicial demostrar las constantes violaciones de derechos humanos que en nuestro país se producen. Estas instancias conceptuales permiten desarrollar estrategias persuasivas que impidan la conculcación de derechos humanos.

Rorty está reduciendo la difusión y propagación de los derechos humanos a una simple cuestión de mera sentimentalidad, despojándolos de su fuerte carácter cognitivo, valorativo y racional en la dirección de una ética privada sentimental banal y frívola como: «Pro-

35 En este sentido, según Rorty, deberíamos traducir la idea de «objetividad» como intersubjetividad o solidaridad y conocimiento como solidaridad. Debemos traducir el deseo de objetividad como el deseo de alcanzar el mayor acuerdo intersubjetivo posible. "Objetividad» ha de entenderse, en definitiva, como «acuerdo» entre los miembros de nuestra comunidad epistémica y otras comunidades, sólo así podrá lograrse un diálogo y comunicación entre todos los participantes. Vid., RORTY, R., La filosofía y el espejo de la naturaleza (trad. de J. M. Esteban), Madrid, Tecnos, 1989. 
ducir generaciones de estudiantes amables, tolerantes, prósperos, seguros y respetuosos con los demás en todas partes del mundo es justamente lo que se necesita para alcanzar una utopía ilustrada. Mientras más jóvenes así podamos criar, más fuerte y más global será nuestra cultura de los derechos humanos» ${ }^{36}$.

Como señala el profesor J. L. Rubio Carracedo: «[...] Rorty ha denunciado todos los intentos planteados, por sustentarse más o menos directamente en el cognitivismo. Pero la denuncia de los abusos congnitivistas no legitima el arrojarse en brazos del irracionalismo y declarar, como hace Rorty, que la solución está en la educación de los sentimientos $[\ldots]{ }^{37}$.

Personalmente, considero que incluso dentro de una concepción pragmática de nuestras instituciones políticas podemos concebir una fundamentación teórica que las legitime, conceptualice y justifique. Esta dicotomía entre teoría y praxis jurídica, no sólo resulta absurda sino irreal, pues como Foucault defiende toda práctica de poder conlleva un discurso epistémico que la arropa. Y la tarea y función principal de la filosofía política y jurídica consiste en servir de instancia fundamentadora de nuestras instituciones políticas y jurídicas.

Cuando hablamos de fundamentación de los derechos humanos no entendemos esta expresión en una sentido "fundamentalista", como sinónimo de «búsqueda de un primer principio indemostrable, a partir del cual pueda deducirse un conjunto de normas morales», sino más bien en un sentido "holista», esto es, atento a la totalidad de las condiciones que hacen posible el fenómeno de fundamentar. Este tipo de fundamentación es el que predicó Kant cuando buscaba las «condiciones de posibilidad» del faktum de la moral ${ }^{38}$.

Norberto Bobbio asevera que es inútil buscar un fundamento absoluto $^{39}$ de los derechos humanos, aduciendo cuatro razones para

${ }^{36}$ RORTY, R., «Derechos humanos, racionalidad y sentimentalidad» en SHUTE S. y HURLEY S., Sobre los derechos Humanos, Madrid, Trotta, 2000, p. 130.

37 RUBIO CARRACEDO, J., "Globalización y Direncialidad en los Derechos humanos» en Revista ALFA Ética y Responsabilidad. El futuro de los derechos humanos, año IV, n. ${ }^{\circ} 8$, pp. 69-91, p. 83. También se puede consultar la reflexión crítica del profesor PANEA MÁRQUEZ, José Manuel, "¿Una ética sin obligaciones universales? Rorty y los derechos humanos» Isegoría (Revista de Filosofía Moral y Política), CSIC, Madrid, n. ${ }^{\circ} 22,2000$, pág. 181-196.

38 Vid., CORTINA, A. y MARTÍNEZ NAVARRO, E., Fundamentos de Filosofía moral, Akal, Madrid, 1996.

39 BOBBIO, Norberto. "Sobre el fundamento de los derechos del hombre», incluido en su libro El problema de la guerra y las vías de la paz, Gedisa, Barcelona, 1982, pp. 117-128. 
justificar su postura. En primer lugar, la vaguedad de la expresión, la variabilidad histórica de los mismos, su heterogeneidad y las antinomias que aparecen entre los derechos invocados por los distintos sujetos. El fundamento absoluto no es sólo una ilusión, sino que a veces ha sido un pretexto para defender posiciones reaccionarias. Aunque como él dice, no se trata de llegar a un fundamento absoluto, sino hallar los diversos fundamentos posibles, variables y plurales. Por tanto, no hay que renunciar a distintos intentos limitados y plurales de argumentación racional ${ }^{40}$ en defensa de los derechos humanos en general y, en particular, tampoco a buscar una adaptación y extensión de los mismos a los nuevos contextos de la sociedad contemporánea.

Sin duda, casi todos los filósofos morales, políticos y jurídicos han resaltado el carácter práctico de la problemática de la fundamentación de los derechos humanos ${ }^{41}$, en la que la reflexión filosófica realiza un seguimiento a la situación política concreta en la que nos hallamos inmersos. El reconocimiento y emergencia de los derechos humanos no sólo se debe, como piensa Rorty, a narrativas tristes y sentimentales, sino al desarrollo progresivo de una cultura sólida y fuerte sobre los derechos humanos propiciada por una mayor investigación y conocimiento ético, jurídico y político.

El conversacionalismo rortyano admite que éste se puede llevar a cabo a través del proceso de persuasión. Y que puede ser resultado de presiones demagógicas sin que tengan necesidad de apelar a ningún principio funcionalista. Este conversacionalismo pragmático rortya$\mathrm{no}^{42}$ de iniciar la conversación sin saber el rumbo al que nos dirigimos me parece falaz, perjudicial y peligroso.

«[...] estos derechos no dependen de ninguna doctrina moral comprensiva o concepción filosófica de la naturaleza humana según la cual, por ejemplo, todos los seres humanos son personas morales y

40 Para profundizar sobre el tema puede consultarse el trabajo AGUILERA PORTALES, Rabel Enrique y ESPINO TAPIA, Diana, «Fundamento, naturaleza y garantías jurídicas de los derechos sociales ante la crisis del Estado social» en Revista Telemática de Filosofía del Derecho, Madrid, n. ${ }^{\circ}$ 10, año 2006, pp. 1-29.

${ }^{41}$ AGUILERA PORTALES, Rafael Enrique, "Concepto y fundamento de los Derechos Humanos en la Teoría Jurídica Contemporánea» en AGUILAR CAVALLO, Gonzalo, 60 años después: Enseñanzas pasadas y desafíos futuros, Santiago de Chile, Chile, Librotecnia, Centro de Estudios Constitucionales de Chile, 2008, pp. 18-76.

${ }^{42}$ Cfr. HABERMAS, J., «El giro pragmático de Rorty» (Trad. Pere Fabra) en Isegoría n. ${ }^{\circ}$ 17, 1995, pp. 5-36, p. 5. La única salida que nos brinda Rorty es una salida privada e individual, basada en la recreación simbólica o poética. Una salida únicamente válida para nosotros a nivel privado, nunca como sujetos activos inmersos en una comunidad política. Nuestra tarea es más poética que política, más estética que ética, más redescriptiva que constructiva. 
tienen igual dignidad $\mathrm{u}$ ostentan ciertos poderes morales e intelectuales particulares que los invisten de esos derechos» ${ }^{43}$.

John Rawls ha contribuido positivamente a insistir en que en las sociedades democráticas, en las que no existe un bien común y único, sino que lo central es el pluralismo y la diversidad de ideas y cosmovisiones. La concepción de justicia no puede derivar de una concepción religiosa, moral o política de vida buena determinada y particular. Los comunitaristas se equivocan en tratar de fundar una comunidad política unificada por un orden moral objetivo. Por tanto, existe una diferencia relevante entre ¿cómo quiero vivir? y la pregunta ¿cómo queremos vivir? Ralws nos habla de un «consenso entrecruzado» (overlapping consensus) ${ }^{44}$.

\section{CONSECUENCIAS POLÍTICAS Y JURÍDICAS DEL PRAGMATISMO RORTYANO}

Los teóricos liberales contemporáneos ${ }^{45}$ obvian este tipo de reflexión procedimentalista pues parten de una concepción metafísica que considera al individuo como previo a la sociedad, como poseedor de derechos naturales ${ }^{46}$. como sujeto racional autosuficiente, aislado de las relaciones sociales, de poder, de lenguaje, de cultura que lo conforman. Rorty combate este tipo de liberalismo político que busca una justificación racional y universal, que cree que las instituciones democráticas serán más estables si pude probarse que fueron elegidas por individuos racionales bajo el velo de ignorancia (Rawls) o en una situación de comunicación no distorsionada (Habermas). El teórico liberal ${ }^{47}$ está obligado a bajar al terreno de las prácticas y los

${ }^{43}$ Cfr. RAWLS, John, «The Law of People», en S. SHUTE Y S. HURLEY (comps.) On Human Rights, 1993, Nueva York, Basic Books, p. 71.

${ }_{44}$ Cfr. RAWLS, John, El liberalismo político, (trad. cast. A. Doménech), Crítica, 1996, pp.165 ss.

45 AGUILERA PORTALES, Rafael Enrique, Teoría política y jurídica contemporánea (Problemas actuales), México, Editorial Porrúa, 2008.

${ }_{46}$ AGUILERA PORTALES, Rafael Enrique, "Universalidad de los derechos humanos y crítica a las teorías de la naturaleza humana en el pragmatismo de Richard Rorty», Revista Universitas (Revista Filosofía, Derecho y política), Universidad Carlos III de Madrid, Instituto de Derechos humanos «Bartolomé de las Casas», vol, V, 2006, pp. 47-75.

${ }^{47}$ Los liberales se han apoyado en la categoría de autonomía, mientras los comunitaritas parten de la categoría de autenticidad. Estamos, por tanto, ante dos categorías ético-políticas opuestas desde las cuales se han articulado estas dos corrientes de pensamiento. Los pensadores liberales (Rawls, Habermas, Dworkin) han insistido en la noción de autonomía como fundamento a partir del cual se construyen la noción de 
problemas de la democracia para construir una ciudadanía democrática.

No obstante, para Habermas habría que conservar al menos un eje seguro para no abandonar la «crítica racional de las instituciones políticas existentes ${ }^{48}$. El filósofo alemán considera que todo aquel que abandone dicho enfoque es irracionalista, porque desecha las nociones que históricamente se han utilizado para justificar las diversas reformas de la historia de las democracias occidentales desde la Ilustración. Por consiguiente, abandonar esta perspectiva "universalista ${ }^{49}$ es traicionar las esperanzas sociales y emancipadoras que han sido nucleares en la política democrática y liberal.

Sin embargo, para Richard Rorty no necesitamos «una crítica de la sociedad liberal». En realidad, lo que necesitamos es aumentar y ampliar nuestras sociedades democráticas, las instituciones liberales y las leyes liberales efectivas en nuestro contexto global. El pensamiento filosófico europeo sigue dominado, por una lado, por la noción marxista de «Ideologikritik» y, por otro lado, por la visión romántica del filósofo como intelectual sutil, perspicaz y sagaz que penetra en el fundamento y naturaleza de las instituciones sociales y políticas $^{50}$ para llegar a su verdadera realidad. Rorty desconfía de estas dos concepciones heredadas de la Ilustración moderna.

En este sentido, considero personalmente que no podemos obviar los factores de legitimación y legitimidad moral de nuestras instituciones democráticas. La legitimidad es un término que hace referencia a un conjunto de valores, procedimientos, exigencias y principios que opera con criterios de justificación de normas e instituciones. La legitimidad equivale a la idea de justicia o justificación ética, con lo que podemos decir que un sistema jurídico-político es legítimo cuando es justo. Un sistema jurídico-político tiene legitimidad o es legítimo cuando sus normas están dotadas de cierta justificación ética aceptable.

derechos básicos individuales. Los comunitaristas, por su parte, han acentuado la noción de autenticidad y han propuesto una concepción de la subjetividad moral más vinculada a la ética concreta. Vid., THIEBAUT, Carlos, Vindicación del ciudadano, Paidós, Barcelona, 1998 WELLMER, Albrecht: «Modelos de libertad en el mundo moderno» en THIEBAUT, C. (eds.) La herencia crítica de la Ilustración, Barcelona, Crítica, 1991.

48 HABERMAS, La inclusión del otro (Estudios de teoría política), Barcelona, Paidos, 1999.

49 BERCIANO VILLALIBRE, Modesto, Debate en torno a la postmodernidad, Madrid, Editorial Síntesis, 1998.

${ }_{50}$ Vid., RORTY, R.: Forjar un país. El pensamiento de izquierdas en los Estados Unidos del siglo XX, Barcelona, Paidós, 1999. 
Igualmente, soy un poco escéptico en que el fin de las ideologías consiga aunarnos a todos en torno a un acuerdo general que posibilite nuestra conveniencia dentro del modelo de convivencia democrática. En este sentido, pensar que un acuerdo exitoso entre individuos no necesita ningún tipo de fundamentación o autoridad moral es un poco arriesgado y peligroso, sobre todo en una sociedad donde la manipulación y condicionamiento de los individuos a través de los medios de comunicación de masas es cada vez mayor, pues perdemos continuamente el rumbo sociopolítico al que queremos dirigirnos.

\section{LIBERALISMO IRONISTA, CONTINGENCIA Y COMUNIDAD POLÍTICA}

Sin duda contingencia, ironía y solidaridad constituyen tres conceptos claves que definen fidedignamente la dimensión política del pragmatismo rortyano. En primer lugar, por contingencia de la comunidad liberal entiende que la cultura de las instituciones políticas de una sociedad democrática liberal están mejor servidas y formuladas por una cultura liberal ironista, es decir, una cultura política que evite distinciones binarias. El léxico filosófico como Verdad, $R a-$ cionalidad, Obligación moral constituye el léxico propio del racionalismo ilustrado, un léxico que no puede proporcionarnos un fundamento sólido para el proyecto político de utopía liberal ironista. Aunque históricamente podamos admitir que pudo ser provechoso y ventajoso sobre todo en los inicios de la democracia liberal, actualmente se ha convertido en un obstáculo para la preservación y el progreso de las sociedades democráticas. En cambio, el léxico nuevo como la noción de metáfora y creación de sí mismo puede resultar más adecuado y ventajosa para el liberalismo político ironista.

Este giro redescriptivo de léxicos puede ayudarnos a reconstruir la democracia liberal en nuestra sociedad contemporánea. En esta línea, autores como Sigmund Freud, Charles Darwin, John Stuart Mill representan intelectuales de alto nivel que nos han enseñado a concebirnos a nosotros mismos como uno de tantos experimentos contingentes de la naturaleza. Pensadores que nos han ayudado a vernos no como la culminación del designio de un plan divino o un proyecto natural sino como resultado de un experimento azaroso, fortuito y aleatorio, un experimento que todavía está por hacerse y completarse constantemente. En este sentido, somos un «experimento de la vida», un producto azaroso y fortuito de este Universo. Incluso Thomas Jefferson y John Dewey utilizaron esta metáfora de «experimento» para describir la democracia liberal norteamericana. 
Igualmente, figuras intelectuales como Nietzsche, James, Freud, Proust, Wittgenstein nos han ilustrado de forma apropiada lo que Rorty denomina: «libertad como reconocimiento de la contingencia ${ }^{51}$, es decir, la concepción según la cual no existe una naturaleza fija, dada e inmóvil de nosotros mismos, sino proyectos abiertos, flexibles y moldeables en constante redescripción personal. Esta concepción antropológica de la libertad como contingencia posibilita la formación de una comunidad liberal plural, abierta y tolerante. En realidad, para Rorty seguimos bajo una losa pesada de metafísica esencialista de la que nos tenemos que desprender.

«Este reconocimiento es la principal virtud de los miembros de una sociedad liberal, y que la cultura de esa sociedad debería tener como objetivo curarnos de nuestra profunda necesidad metafísica» ${ }^{52}$.

El principal error de la mayor parte de la tradición de Filosofía moral y política occidental consiste en el mito de un yo no relacional: un yo que puede existir sin preocuparse por los demás, un yo visto como un frío psicópata que es preciso reprimir para poder tener en cuenta las necesidades de la demás gente. Esta es la imagen antropológica que hemos heredado de Platón y que perdura en nuestros días. Por tanto, la tarea que debemos realizar es superar la tradicional dicotomía entre formas racionales e irracionales de persuasión, entre razón y voluntad, entre razón y pasión, pues no hay forma de trazar una línea precisa entre ambas realidades.

«Que lo que finalmente importa son los cambios de léxico antes que los cambios de creencia, los cambios en los candidatos a poseer el valor de verdad y no las asignaciones de valor de verdad $»^{53}$.

En consecuencia, no existe diferencia ni demarcación nítida entre el diálogo socrático y la sugestión hipnótica, entre el lavado de cerebro y medios publicitarios. Rorty considera que es imposible trazar una línea divisoria entre la persuasión y la fuerza, argumentación y demagogia. En esta línea, combate la distinción clásica entre episteme

${ }^{51}$ En esto, sigue la tradición emprendida por Freud, Darwin y Mill, por la cual deberíamos concebirnos a nosotros mismos como uno de tantos experimentos de la naturaleza y no como la realización finalista y teleológica del designio de la naturaleza, Dios u otra instancia superior. Por tanto, somos un experimento social e individual de vida, incluso, la democracia sería un experimento más entre otros, un experimente frágil, contingente y vulnerable. Vid. HOOK, Sidney, Pragmatism and the tragic sense of life, Basic Books, Nueva York, 1974.

${ }_{52}$ RORTY, R.: Contingencia, ironía y solidaridad. Barcelona, Paidós, 1991, p. 65.

53 Ibid., p. 67. 
y doxa que permea toda la historia del pensamiento científico y filosófico occidental.

«Aceptar la afirmación de que no hay un punto de vista fuera del léxico particular, históricamente condicionado y transitorio, que utilizamos ahora, desde el cual juzgar ese léxico, es renunciar a la idea de que puede haber razones para el empleo de lenguajes, y así mismo, de que puede haber razones dentro de los lenguajes para creer en las afirmaciones ${ }^{54}$.

Incluso, debemos renunciar a la idea de que todo progreso intelectual y político en nuestra historia es racional. Los grandes avances morales e intelectuales de la historia de Europa como la aparición del cristianismo, la ciencia de Galileo, la ilustración, el romanticismo, el positivismo fueron afortunadas caídas en una irracionalidad temporal $^{55}$. La distinción entre lo racional e irracional ha sido menos útil históricamente de lo que pueda parecer.

La noción de progreso moral y político constituye una cuestión de simple uso de palabras, términos o nociones nuevas, es decir, una cuestión meramente nominal e instrumental. El léxico que gira en torno a nociones como «racional», «criterio», «argumento» $O$ "fundamento» no es apto en la actualidad para describir la relación entre sociedad tradicional y moderna, sociedad antigua y nueva.

En esta línea, el pragmatismo rortyano se apoya en el pensamiento científico de Davidson quien critica la concepción fuerte de racionalidad, y observa que si renunciamos a la noción de «criterios absolutos de racionalidad» ${ }^{56}$ como sinónimo de "coherencia interna», entonces nos veremos forzados a llamar «irracional» a muchos cosas, como por ejemplo, una forma de autocrítica y reforma que tenemos en alta estima y que siempre hemos considerado como la esencia misma de la racionalidad y una fuente de la libertad.

En este aspecto, si Davidson se equivoca en sus tesis, no existe un marco máximo en el cual supongamos que la libertad posee una condición moralmente privilegiada. No podemos suponer, según Rorty, que los liberales públicos deban ser capaces de elevarse por encima de las contingencias históricas políticas y observar, de este

${ }_{54}$ Ibid., p. 67.

55 FEYERABEND, P., La ciencia en una sociedad libre. (trad. A. Elena), Siglo XXI, 1982; también puede consultarse otros trabajos suyos cómo: ¿Por qué no Platón? Madrid, Tecnos, 1985; Adiós a la razón. (trad. J. R. de Rivera), Madrid, Tecnos, 1989.

56 DAVIDSON, D., "A Coherence Theory of Truth and Knowledge», Malachowski, A., Reading Rorty, Massachusetts, Blackwell, 1990. 
modo, la especie de libertad individual que el Estado liberal moderno ofrece a sus ciudadanos como un valor superior entre otros.

Otros candidatos en la historia como por ejemplo los nazis pusieron lo racional en el sentimiento de alcanzar una meta nacional para el pueblo alemán y durante la guerra de religiones del siglo XVII lo racional procedía de la defensa de una determinada confesión religiosa o durante las cruzadas medievales lo racional consistía en el sentimiento de obediencia a la voluntad de Dios. Por consiguiente, para Rorty, no existen valores morales absolutos, ni privilegiados o superiores, ni podemos ponernos en una perspectiva más elevada desde la cual poder dar cuenta de cuáles son los valores prioritarios y fundamentales. Lo que denominamos racional es relativo a cada contexto histórico y comunidad epistémica.

"Una sociedad liberal es aquella que se limita a llamar "verdad" al resultado de los combates sea cual fuere ese resultado. Esa es la razón por la que se sigue mal a una sociedad liberal con el intento de dotarla de fundamentos filosóficos $[\ldots] \aleph^{57}$.

El pragmatismo rortyano utiliza el aporte de Davidson al considerar que no podemos desprendernos de nuestros esquemas conceptuales propios (contingentes) dependientes de una comunidad epistémica concreta que nos permita comparar distintos y variados esquemas conceptuales y discutir que valores son los privilegiados ( «la visión del ojo de Dios» putniano).

Por consiguiente, resulta estéril y superfluo fomentar una búsqueda de fundamento externo a la sociedad liberal, más bien lo que debemos hacer es fomentar la sociedad liberal por sí misma. Una sociedad liberal es aquella comunidad que se limita llamar «verdad ${ }^{58}$ al resultado de los combates intelectuales sea cual sea su resultado. En este aspecto servimos mal a una sociedad liberal intentando dotarla de "fundamentos filosóficos», porque dotarla de tales fundamentos presupone un orden natural de temas y argumentos que es anterior a la confrontación entre viejos y nuevos léxicos. Y en consecuencia esta estrategia fundacionalista anula el resultado de la indagación y discusión intelectual.

57 DAVIDSON, D., Mente, mundo y acción. (trad. C. Moya), Barcelona, Paidós, 1992.

58 RORTY, Contingencia, ironía y solidaridad. Barcelona. Paidós. 1991, pp. 61-71. La verdad, por tanto, es un producto resultante de una discusión pública, abierta y libre, no el resultado de una representación acertada y exacta de la realidad, pero esta discusión pública no tiene guía ni dirección y menos aún normas por las que regularse. Rorty irrumpe en un fuerte relativismo epistemológico del cual es difícil deprenderse. 
Nuestra cultura democrática liberal necesita una redescripción de sí misma antes que un conjunto de argumentos, justificaciones y fundamentos. La necesidad imperiosa y urgente de búsqueda de fundamentos ha sido el resultado histórico del cientificismo y racionalismo ilustrado ${ }^{59}$, como un intento de supervivencia ante la necesidad religiosa de disponer de proyectos humanos avalados por una autoridad no humana. En definitiva, constituyen intentos secularizados que surgieron con la modernidad política y científica.

«Necesitamos una reedescripción del liberalismo como la esperanza de que la cultura en su conjunto pueda ser "poetizada", y no como la esperanza de la Ilustración de que se la pueda "racionalizar" o tornar "científica" ${ }^{60}$.

Una cultura liberal poetizada, según Rorty, renunciaría a la idea de justificación racional del liberalismo político y, también, a tratar de refutar a los adversarios nazis o marxistas, poniendo a estos últimos contra un nuevo argumento que consideramos superior, es decir, forzándolos a admitir que la libertad surgida del liberalismo político tiene un «privilegio moral» que conocen los que la defienden. Una cultura poetizada ${ }^{61}$ admite la pluralidad de léxicos, valores $\mathrm{y}$ argumentos en pie de igualdad sin necesidad de tener que responder a la acusación de relativismo epistemológico, moral o político.

${ }^{59}$ La cultura política ilustrada fue el fundamento intelectual del reformismo. Los intelectuales ilustrados teorizaron el protagonismo de los filósofos como motor de la modernización, la prioridad del fomento económico, la utilización de la crítica como herramienta para el perfeccionamiento de la organización social, la aplicación del conocimiento científico al bienestar general, la finalidad educativa de la creación literaria y artística, el progreso y la felicidad como metas últimas del pensamiento y la práctica reformistas. La Ilustración se dotó de sus propios instrumentos de difusión cultural que al mismo tiempo lo eran de acción reformista: las academias, las universidades intervenidas para acompasarlas a las exigencias del momento, una serie de nuevas instituciones de enseñanza superior, las Sociedades Económicas de Amigos del País, los consulados y la letra impresa en libros o en publicaciones periódicas. La Ilustración finalmente obtuvo resultados muy considerables en todos los campos: el pensamiento económico, la crítica social, la renovación eclesiástica, el pensamiento científico y la producción literaria y artística. Vid., ABELLÁN, J. L.: Historia crítica del pensamiento español. Volumen III (Del Barroco a la Ilustración), Espasa-Calpe, Madrid, 1988, (2. a edición); DOMÍNGUEZ ORTIZ, A.: Sociedad y Estado en el siglo XVIII español. Ariel, Barcelona, 1984, (2. ${ }^{\text {a reimpresión }) .}$

${ }^{60}$ Ibid., p. 72.

61 Si los ingenieros y los científicos naturales nos ayudan a mejorar nuestra vida material, los poetas y los novelistas contribuyen a que nos hagamos más amables, solidarios y tolerantes. La cultura poetizada se apoya en la tesis de inconmensurabilidad de paradigmas defendida por Kuhn. 
En consecuencia, debemos aprender a dejar a un lado preguntas de ámbito público como: ¿Como sabe usted que la libertad es la meta principal de la organización política? del mismo modo que obviar preguntas para el ámbito privado como: ¿cómo sabe que alguien es digno de su amistad? O ¿cómo sabe que Yeats es un poeta importante, Hegel un filósofo importante y Galileo un científico importante?

Richard Rorty adopta la teoría de la inconmensurabilidad de paradigmas $^{62}$ de Kuhn y Feyerabend respecto a la elección de modelos científicos haciéndola extensible al campo filosófico, epistemológico y político. Estos pensadores defienden un relativismo epistemológico donde no existen criterios objetivos, racionales y neutrales que permiten fundamentar la elección de un determinado paradigma, de forma parecida ocurriría con la búsqueda de fundamentos racionales de nuestro liberalismo político.

En primer lugar, la tesis de Rorty es que las instituciones liberales pueden sobrevivir a la caída de sus fundamentos filosóficos, es más, rehusar a tal intento fundacionalista puede contribuir a mejorar y perfeccionar nuestras instituciones políticas liberales. En segundo lugar, el concepto de ironía no es un término clave que pueda ayudarnos a respaldar la vida de una sociedad democrática, pues su práctica es exclusivamente privada como autorrealización individual. En tercer lugar, la solidaridad a la que se refiere Rorty nos remite a una concepción de disposición cooperativa individual dentro de una comunidad cultural concreta.

«El éxito o fracaso de la estrategia rortyana se juega en la posibilidad de hacer compatibles contingencia, ironía y solidaridad. En concreto, esta última noción es la que está sometida a mayores tensiones, pues resulta difícil imaginar la idea de una solidaridad extensa si no es entendiéndola como proceso que conduce hacia una meta ${ }^{63}$.

${ }^{62}$ La inconmensurabilidad de paradigmas científico rivales ha suscitado numerosos debates en la teoría de la ciencia actual, pero podríamos caracterizar tres tipos de diferencias entre un paradigma y su rival. En primer lugar, diferentes problemas, concepciones y definiciones de ciencia, en segundo lugar, diferencias conceptuales entre ambos paradigmas (diferencias entre lenguaje teórico e interpretación ontológica) $\mathrm{y}$, en tercer lugar, diferentes visiones del mundo o cosmovision. Vid., ECHEVERRIA, Javier, Introducción a la metodología de la ciencia (la Filosofía de la ciencia en el siglo veinte), Barcelona, Barcanova, 1989, p. 115. Rorty hace suya esta teoría para indicar la disolución de los cánones tradicionales del saber entre ciencia y no ciencia.

${ }^{63}$ Cfr. GREPPI, Andrea, «Democracia sin fundamentos: pragmatismo y deconstrucción» en Concepciones de la democracia en el pensamiento político contemporáneo, Madrid, Trotta, 2007, p. 154. 
El problema que debe afrontar la teoría política rortyana es cómo construir una noción suficientemente consistente de solidaridad sin progreso, es decir, cómo construir un modelo democrático amplio de solidaridad desde una posición de relativismo epistemológico y político carente de dirección política. La solidaridad no consiste en un valor de ética privada, sino un valor normativo que fundamenta un modelo de Estado social que propugna una verdadera igualdad de oportunidades a todos los miembros de su sociedad. 